\title{
Can Stock Price Manipulation be Prevented by Granting More Freedom to Manipulators
}

\author{
Deniz Ilalan ${ }^{1}$ \\ ${ }^{1}$ Department of Banking and Finance, Cankaya University, Ankara, Turkey \\ Correspondence: Deniz Ilalan, Department of Banking and Finance, Cankaya University, Eskisehir Yolu 29. Km, \\ Ankara, 06810, Turkey. Tel: 90-312-233-1200. E-mail: denizilalan@cankaya.edu.tr
}

Received: December 24, 2014

Accepted: January 13, 2015

Online Published: February 25, 2015

doi:10.5539/ijef.v7n3p179

URL: http://dx.doi.org/10.5539/ijef.v7n3p179

\begin{abstract}
Allen and Gale (1992) construct a model to show that stock price manipulation is possible. The time structure of their model allows manipulators to pretend as "informed" traders, so that the local investors cannot distinguish what type of entrant they are facing. When the type of the entrant becomes known to the local investors it is already too late to make any use of that information. This paper shows an institution can be designed in a very natural fashion which induces different behaviors on the part of manipulators and "informed" traders at the beginning of the process. The institution designed roughly consists of entitling the entrants to resell stocks at a later date as well if they wish to do so. As this reasoning is also accessible to manipulators, the designed institution deters them from entering the market. Regarding the informed traders, their expected gain from entering the stock market may or may not be positive contingent on the basic parameters of the model. There are cases, however, when there is an improvement in the expected total gain of the local investors.
\end{abstract}

Keywords: stock market, manipulation, equilibrium price, institutional design

\section{Introduction}

Manipulation is a major issue for stock markets. Releasing false information about the future in an attempt to change the society's beliefs about stocks is one way of manipulating the stock prices. This type of manipulators usually spread false information and try to chance the society's beliefs. This kind of manipulation can be classified as information based and is regarded as illegal. Another kind is action based manipulation. Here manipulators sell more stocks than they actually own. The signal such an action leads to, conjoined with again spreading false information is expected to force the price down. Now the manipulators can buy additional stocks at this low price and cover their short position. This kind of manipulation is also often ruled out by law. The third kind of manipulation, which is trade based, is not only legal but also hard to observe. It occurs when a trader attempts to alter the stock prices simply through buying and selling. There is no false information spreading or short selling involved here. At first glance trade based manipulation may seem unprofitable. When a trader buys a stock he drives the price up, if he sells he drives the price down. Thus, one expects trade based manipulation to be impossible in an efficient market. Actually, this has been shown to be true under certain conditions by Jarrow (1992).

Allen and Gale (1992), on the contrary, construct a model. Here trade based manipulation is possible even though all agents are fully rational.

This study approaches the model by Allen and Gale from a wider rationality angle, allowing the investors to design new institutions as well in case they find these beneficial. Simply entitling the entrants to resell the stocks they bought also at a later date than in Allen and Gale model if they wish to do so. This turns out to yield valuable information to the investors at the outset of the entire process. Namely, instituting the above time structure induces different actions on the part of manipulators and "informed" traders at date 1, rendering pretension of "informed" traders unprofitable for manipulators. Getting deciphered so early deters manipulators' entry, by inducing their expected gains to nil. The absence of manipulators also has an impact upon the "informed" traders, of course. It turns out that, for certain values of the basic parameters, they still have an incentive to enter the stock market, while, for other values of these, they prefer to stay out as well. For some cases, the investors benefit from the new institution. 
The remaining study is organized as follows: Section 2 gives a brief summary of Allen and Gale (1992). Section 3 is about the new institution obtained from the Allen and Gale model through a modification of its time structure. It is shown this modification closes the market to manipulation. A numerical example where the outcomes of the two models are being compared is given in Section 4. Finally, Section 5 closes the paper with some concluding remarks.

\section{Stock Price Manipulation" by Allen and Gale (1992) - Summary}

The article Allen and Gale (1992) demonstrates the possibility of profitable trade based manipulation. False information release or insider trading is not present in this model. There is an uninformed speculator who does not have any privileged information about the value of the stock in the future. Other than the uninformed speculator there is also an informed trader. The informed trader has a conjecture about the value of the stock because of research he has done or access he has had to inside information. When entry takes place the local investors can not distinguish whether the entrant is informed or not. In this kind of framework the uninformed speculator called the manipulator can make profit, provided that the investors attach a positive probability to the manipulator being an informed trader due to the asymmetry of information.

Trading takes places at three dates indexed by $t=1,2$ and 3. Cash and stock are the assets in this model. Throughout the model there is no discount factor or depreciation. As described above there are three types of traders: a continuum of identical investors and two large traders, an informed trader and a manipulator. Investors act as price takers.

The large traders can be treated as risk neutral assuming the stock has no value after date 3 , hence they only care about money. The investors can be treated as risk averse since the fraction of their wealth held in the stock is large enough.

With probability $\alpha$ an announcement is made about the value of the stock. The informed trader knows when an announcement is forthcoming other traders do not. When there is an announcement to be made, with probability $\pi$ it is "good news" which indicates that the value of the stock will be high (denoted by $V_{H}$ ). With probability $1-\pi$ it is "bad news" which indicates that the value of the stock will be low (denoted by $V_{L}$ ). There are no other values available for a stock and $V_{H}>V_{L}$. At the end of the session it is either one of these two. If an announcement is "good news" it is made at date 3, if it is "bad news" it is made at date 2 . This is one of the most crucial assumptions made in this article. Bad news is always released before good news.

At the beginning, only investors are present in the stock market. They hold all of the stock initially. The total amount of stocks in the market (the investors' endowment) is denoted by $E$ where $E>0$.

The informed trader only enters the market if he anticipates an announcement (with probability $\alpha$ ). Otherwise he stays out. If there is no announcement in the future, the manipulator may enter the market (with probability $\beta$ ). With probability $1-\alpha-\beta$ there is no entry.

If the informed trader enters the market he is the only large trader present and is aware of the fact. The manipulator only enters the market if no information is expected. In other words, the manipulator knows there will be no informed trader in the market. However, the investors cannot distinguish the type of entrant.

All traders wish to maximize their final wealth. This is wealth at date 2 for the large trader (whatever his type may be) and wealth at date 3 for the investors. The investor is risk averse and his preferences are represented by a von Neumann- Morgenstern utility function $U$ where $U$ is twice continuously differentiable with $U^{\prime}>0$ and $U^{\prime \prime}<0$

If no entry takes place on date 1 , there is no trade; the stock's true value and the equilibrium price is $V_{L}$. It has been assumed that if a large trader enters the market he purchases $B>0$ units of stock regardless of his type. At date 2 he sells his entire holding of $B$ units and leaves the market. If there is an announcement at date 2 , which is "bad news", the true value of the stock will be $V_{L}$ and this will be publicly known and become the equilibrium price. In this case the large trader must be informed. If there is no announcement on date 2 , there is positive probability that the true value of the stock will be high. In this case "no news" is "good news" and this drives the price up. However there is also positive probability that the entrant is a manipulator and there will not be an announcement on date 3 , which reveals the true value of the stock to be $V_{L}$. The informed trader and the manipulator are pooling and the equilibrium price reflects the uncertainty of the investor about the true value of the stock.

At date 3 the investors are alone in the market, holding the initial endowment of the stock. Either there is an announcement that the stock's value will be $V_{H}$ or $V_{L}$. Since no large trader is present there can be no trade and the equilibrium price is the true value of the stock. 
The figure below depicts the timeline and information structure of the market.

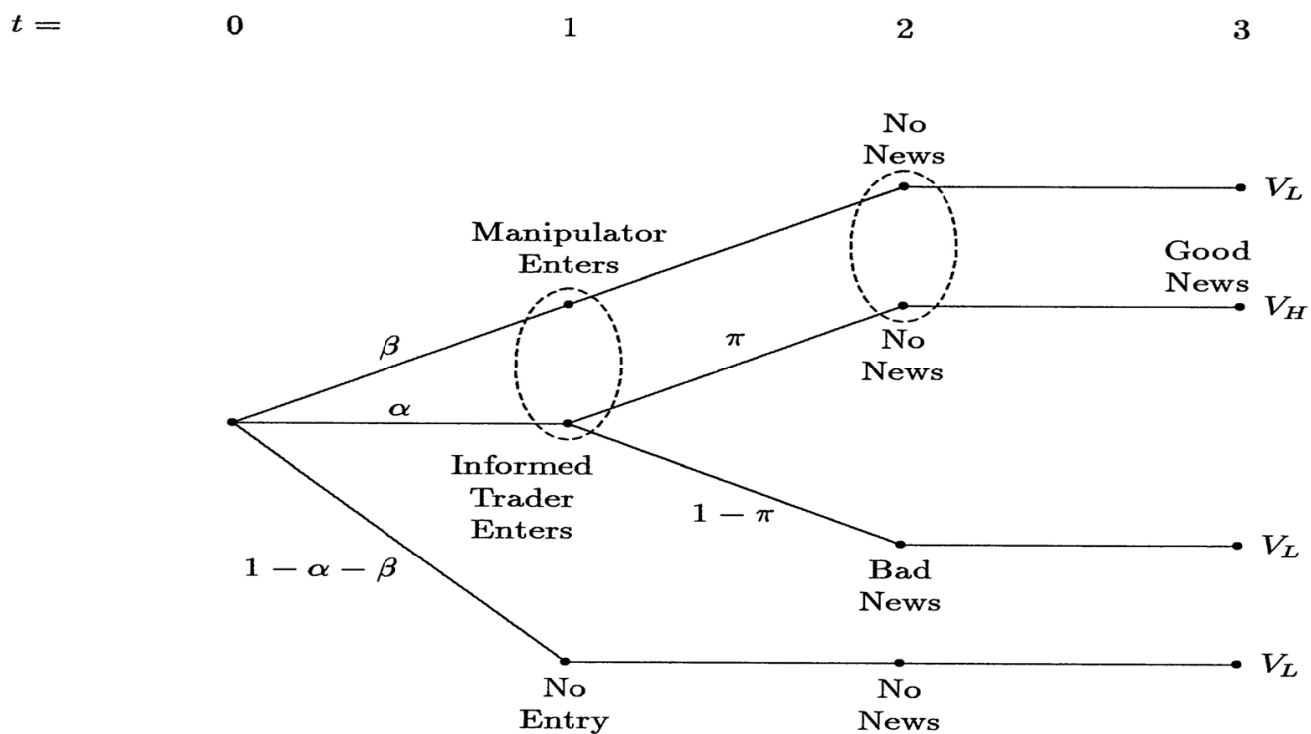

Figure 1. Timeline and information structure of the market

Equilibrium is characterized by backward induction. There is no analysis needed for date 3 since everyone knows the value of the stock at date 3 .

For the equilibrium at date 2 several cases have to be considered and distinguished.

\section{Equilibrium at date 2.}

\section{i. A large trader did not enter at date 1}

In this case no further analysis is required since no trading occurs. It has been assumed that this absence reveals the true value of the stock as $V_{L}$. This is also the equilibrium price.

\section{ii. A large trader entered the market at date 1}

If a large trader enters the market he is assumed to buy $B>0$ units of stock at price $P_{l}(B)$ regardless of his type. The entrant is informed with probability $Q_{l}(B)=\alpha /(\alpha+\beta)$. There can be two situations:

\section{iii. An announcement is made at date 2}

In this situation there is "bad news" which indicates that the true value of the stock as $V_{L}$. Since this is publicly known it becomes the equilibrium price $P_{2}(B)=V_{L}$. The large trader who must be informed sell his entire holding $B$ and the investors are willing to purchase that amount since there is no uncertainty

\section{iv. No announcement is made at date 2}

In this case the investors are uncertain about the type of the entrant. If he is an informed trader then there will be an announcement, "good news", which reveals the true value of the stock to be $V_{H}$. If the entrant is a manipulator then there will be no announcement at date 3 , which reveals the true value of the stock to be $V_{L}$.

The investor's objective is to maximize his utility taking the price at date 1 , namely $P_{l}(B)$ as given and compute the market-clearing price $P_{2}(B)$. Here $P_{2}(B)$ actually denotes the "demand" of the investors'.

Let $Q_{2}(B)=Q_{l}(B) \pi /\left[Q_{l}(B) \pi+1-Q_{l}(B)\right]$ denote the posterior probability that the large trader is informed given that no announcement has been made at date 2 .

Equilibrium price is computed from investors' first order condition as:

$$
P_{2}(B)=\frac{V_{H} Q_{2}(B) U^{\prime}\left(W_{H}(B)\right)+V_{L}\left(1-Q_{2}(B)\right) U^{\prime}\left(W_{L}(B)\right)}{Q_{2}(B) U^{\prime}\left(W_{H}(B)\right)+\left(1-Q_{2}(B)\right) U^{\prime}\left(W_{L}(B)\right)}
$$

where,

$W_{H}(B)=E V_{H}+\left(P_{l}(B)-P_{2}(B)\right) B$ (no news is announced at date 2 and the entrant is an informed trader, hence 
the stock's true value is $\left.V_{H}\right)$.

And $W_{L}(B)=E V_{L}+\left(P_{l}(B)-P_{2}(B)\right) B$ (no news is announced at date 2 and the entrant is a manipulator, hence the stock's true value is $V_{L}$ )

\section{Equilibrium at date 1.}

We know that no further analysis is required when there is no entry at date 1 . The equilibrium price is $V_{L}$ for all dates. If there is an entry, the entrant purchases $B>0$ amount of stock regardless of his type since the informed trader and the manipulator pool at date 1 .

In the second period one of the 3 situations might happen to the representative investor:

i. With probability $Q_{l}(B)(1-\pi)$ the entrant is informed and bad news is announced at date 2 . Hence the representative investor's final wealth will be $W_{L}(B)=E V_{L}+\left(P_{l}(B)-V_{L}\right) B$.

ii. With probability $Q_{l}(B)(1-\pi)$ the entrant is again informed but good news is announced at date 3 . Hence the representative investor's final wealth will be:

$$
W_{H}(B)=E V_{H}+\left(P_{1}(B)-P_{2}(B)\right) B
$$

iii. With probability $\left(1-Q_{l}(B)\right)$ the entrant is the manipulator and no news will be forthcoming. Hence the representative investor's final wealth will be:

$$
W_{M}(B)=E V_{L}+\left(P_{1}(B)-P_{2}(B)\right) B
$$

Using these formulas the representative investor maximizes his expected utility and then computes the market clearing price $P_{l}(B)$ which is:

$$
P_{1}(B)=\frac{Q_{1}(B) \pi U^{\prime}\left(W_{H}(B)\right) V_{H}+Q_{1}(B)(1-\pi) U^{\prime}\left(W_{L}(B)\right) V_{L}+V_{L}\left(1-P_{1}(B)\right) U^{\prime}\left(W_{M}(B)\right) V_{L}}{Q_{1}(B) \pi U^{\prime}\left(W_{H}(B)\right)+Q_{1}(B)(1-\pi) U^{\prime}\left(W_{L}(B)\right)+V_{L}\left(1-Q_{1}(B)\right) U^{\prime}\left(W_{M}(B)\right)}
$$

It has been implicitly assumed that $B$ is the equilibrium choice. For any amount other than $B$ assume that the investor believes entrant is the manipulator. In this situation the equilibrium price is $V_{L}$. It is impossible for the large trader to make arbitrage payoff in this situation. $B$ is optimal for the large trader (both types) if the informed trader's payoff is nonnegative $\pi P_{2}(B) B+(1-\pi) V_{L} B-P_{l}(B) B \geq 0$ which implies that the manipulator's payoff $\left(P_{2}(B)-P_{l}(B)\right) B \geq 0$. These conditions and $P_{l}(B)$ defines a pooling equilibrium.

Proposition: As long as the investors are sufficiently risk averse and the probability of manipulation $\beta$ is sufficiently small, there exists a pooling equilibrium at date 1 in which the manipulator achieves strictly positive profits.

If the manipulator's type had been revealed the price profile would be $\left\{V_{L}, V_{L}, V_{L}\right\}$. However in this setup the price profile is: $\left\{P_{I}(B), P_{2}(B), V_{H}\right.$ or $\left.V_{L}\right\}$.

Some auxiliary assumptions have been made in Allen and Gale (1992) for the selling amount $B$ to be optimal. First it is been assumed that the market clearing price $P_{2}(B)$ is uniquely determined for every initial condition. Also the investors beliefs are not effected if the informed trader attempts to buy more than he is able to sell. The large trader might be better of by selling less than $B$ units in the equilibrium. Since he is acting as a monopolist he might be better off by restricting supply. However, in this situation he might be even better off by buying less than $B$ units. Hence selling what is bought is again optimal. Trading might occur more that once. The large trader always wishes to sell his holdings if the price is positive. The manipulator keeps on imitating the informed trader. Since investors will only buy at the lowest price, trade can occur at a single price that is determined by the market clearing condition.

Another critical assumption that is considered in Allen and Gale (1992) is the impatience of the traders. The informed trader and the manipulator sell their entire holdings at date 2. The manipulator always finds it optimal to imitate the informed trader. It is been assumed that the informed trader has more profitable job opportunities if he leaves the market at date 2. If he waits until the prices become public his opportunity might be lost. There is also a small discount for the informed trader that the investors between date 2 and date 3 . Hence the informed trader has an incentive to liquidate his entire holding at date 2.

\section{How to Prevent Trade Based Stock Price Manipulation}

In Allen and Gale (1992) the large trader is restricted to liquidate his entire holding at date 2 only. Now let us relax this ad-hoc assumption and allow the large trader to liquidate his entire holding not only at date 2 but also at date 3 if he prefers to do so. 
In this new setup again further analysis is not required when there is no entry. The equilibrium price is always $V_{L}$ since there is no trade. The probability of this event to occur is $1-\alpha-\beta$ as before.

If there is an entry there are 3 cases to be considered:

Case 1: With probability $Q_{I}(B)(1-\pi)$ where $Q_{l}(B)=\alpha /(\alpha+\beta)$ the entrant is an informed trader and the stock's value will be $V_{L}$. This value will be publicly known and also become the equilibrium price at date 2. The large trader will sell his entire (which he bought at date 1) holding at price $V_{L}$ at date 2.

Case2: With probability $Q_{l}(B) \pi$ the entrant is again informed but there is no bad news at date 2 and the stocks' value will be $V_{H}$ at date 3 . Since the informed trader is able to sell his holdings also at date 3 , it is dominant strategy for him to wait till the price of the stock is publicly known and sell it at $V_{H}$ afterwards.

Case3: With probability $1-Q_{I}(B)$ the entrant is a manipulator. However in this situation he can only sell his entire holding at $V_{L}$. The reasoning is as follows: If the large trader wishes to sell his entire holding at date 2 for a price less than $V_{H}$, the investors will infer that the entrant is not an informed trader provided that he acts rationally. If he attempts to sell at price $V_{H}$ at date 2, it is dominant for the investors to wait until date 3 to buy any stocks. The investors will only repurchase any stock from a manipulator at price $V_{L}$. Other selling prices greater than $V_{L}$ will be rejected. If the manipulator chooses to wait until the value of the stock is publicly known (date 3), then the price will again be $V_{L}$ since no good news will be announced. As a conclusion, the manipulator can only sell his entire holding at $V_{L}$; thus he will not buy any stocks at date 1 for a price higher than $V_{L}$ !

As the large trader is assumed to derive utility from money only (and none from the stocks) at the end of date 3 and the exact value of the price of the stock becomes publicly known, it is beneficial for him to sell his entire holding. Now let us derive the investors' supply function at date $1, P_{1}^{*}(B)$ by taking into account the prevailing market clearing prices at date 2 and date 3. Since there is no discount between date 2 and date 3 we can combine them.

The representative investor wishes to maximize his utility. Here again we assume that $U$ is a Von-Neumann Morgenstern, twice continuously differentiable utility function with $U^{\prime}>0$ and $U^{\prime \prime}<0$.

Representative investor's objective is to maximize

$$
\begin{aligned}
Q_{1}(B) \pi U\left(W_{H}^{*}(B)\right)+Q_{1}(B)(1-\pi) U\left(W_{L}^{*}(B)\right)+\left(1-Q_{1}(B)\right) U\left(W_{M}^{*}(B)\right) \text { where } \\
W_{H}^{*}(B)=E V_{H}+\left(P_{1}^{*}(B)-V_{H}\right) B, \\
W_{L}^{*}(B)=E V_{L}+\left(P_{1}^{*}(B)-V_{L}\right) B, \\
W_{M}^{*}(B)=E V_{L}+\left(P_{1}^{*}(B)-V_{L}\right) B
\end{aligned}
$$

Notice that $W_{L}^{*}(B)=W_{M}^{*}(B)$. Hence the maximization problem reduces to

$$
\operatorname{Max} Q_{1}(B) \pi U\left(W_{H}^{*}(B)\right)+\left(1-Q_{1}(B) \pi\right) U\left(W_{L}^{*}(B)\right)
$$

with respect to $B \in[0, E]$ for any given $P_{1}^{*}(B)$.

$$
\begin{gathered}
\left(P_{1}^{*}(B)-V_{H}\right) Q_{1}(B) \pi U^{\prime}\left(W_{H}^{*}(B)\right)+\left(P_{1}^{*}(B)-V_{L}\right)\left(1-Q_{1}(B) \pi\right) U^{\prime}\left(W_{L}^{*}(B)\right)=0 \\
P_{1}^{*}(B)=\frac{V_{H} Q_{1}(B) \pi U^{\prime}\left(W_{H}^{*}(B)\right)+V_{L}\left(1-Q_{1}(B) \pi\right) U^{\prime}\left(W_{L}^{*}(B)\right)}{Q_{1}(B) \pi U^{\prime}\left(W_{H}^{*}(B)\right)+\left(1-Q_{1}(B) \pi\right) U^{\prime}\left(W_{L}^{*}(B)\right)}
\end{gathered}
$$

Facing this supply function the manipulator's expected profit is less than or equal to 0 since he can at most sell his holdings to $V_{L}$ and any prevailing market clearing price $P \in\left[V_{L}, V_{H}\right]$. Hence the manipulator prefers to stay out of the stock market. He is only indifferent between entering and staying out when his expected profit is 0 . This only happens when $P_{1}^{*}(B)=V_{L}$. Let us check whether this is possible or not. $P_{1}^{*}(B)=V_{L}$ is actually

$$
\begin{gathered}
\frac{V_{H} Q_{1}(B) \pi U^{\prime}\left(W_{H}^{*}(B)\right)+V_{L}\left(1-Q_{1}(B) \pi\right) U^{\prime}\left(W_{L}^{*}(B)\right)}{Q_{1}(B) \pi U^{\prime}\left(W_{H}^{*}(B)\right)+\left(1-Q_{1}(B) \pi\right) U^{\prime}\left(W_{L}^{*}(B)\right)}=V_{L} \\
V_{H} Q_{1}(B) \pi U^{\prime}\left(W_{H}^{*}(B)\right)+V_{L}\left(1-Q_{1}(B) \pi\right) U^{\prime}\left(W_{L}^{*}(B)\right)=V_{L} Q_{1}(B) \pi U^{\prime}\left(W_{H}^{*}(B)\right)+V_{L}\left(1-Q_{1}(B) \pi\right) U^{\prime}\left(W_{L}^{*}(B)\right) \\
V_{H} Q_{1}(B) \pi U^{\prime}\left(W_{H}^{*}(B)\right)=V_{L} Q_{1}(B) \pi U^{\prime}\left(W_{H}^{*}(B)\right) \\
V_{H}=V_{L}
\end{gathered}
$$

Which is impossible since $V_{H}>V_{L}$ is the basic assumption of Allen and Gale and this paper. Hence we conclude 
the manipulator never enters the stock market when we allow trading not only at date 2 but also at date 3 . With this new information the investors revise and update their beliefs. The equilibrium price is always $V_{L}$ when there is no entry. If there is an entry the entrant is with probability 1 informed. Hence the representative investor's objective is:

$$
\operatorname{Max} \pi U\left(W_{H}^{*}(B)\right)+(1-\pi) U\left(W_{L}^{*}(B)\right)
$$

subject to $B \geq 0$.

$$
\begin{gathered}
\left(P_{1}^{*}(B)-V_{H}\right) \pi U^{\prime}\left(W_{H}^{*}(B)\right)+\left(P_{1}^{*}(B)-V_{L}\right)(1-\pi) U^{\prime}\left(W_{L}^{*}(B)\right)=0 \\
P_{1}^{*}(B)=\frac{V_{H} \pi U^{\prime}\left(W_{H}^{*}(B)\right)+V_{L}(1-\pi) U^{\prime}\left(W_{L}^{*}(B)\right)}{\pi U^{\prime}\left(W_{H}^{*}(B)\right)+(1-\pi) U^{\prime}\left(W_{L}^{*}(B)\right)}
\end{gathered}
$$

The informed trader's expected price before the value of the stock becomes public is $\pi V_{H}+(1-\pi) V_{L}$. The informed trader only enters the stock market when

$$
\pi V_{H}+(1-\pi) V_{L}>\frac{V_{H} \pi U^{\prime}\left(W_{H}^{*}(B)\right)+V_{L}(1-\pi) U^{\prime}\left(W_{L}^{*}(B)\right)}{\pi U^{\prime}\left(W_{H}^{*}(B)\right)+(1-\pi) U^{\prime}\left(W_{L}^{*}(B)\right)}
$$

$\mathrm{He}$ is indifferent between entering or staying out if the above inequality holds with equality. He stays out when the inequality holds in the opposite direction.

Before stating the informed trader's revenue maximization problem, remember that the amount bought by the large trader at date 1 will equal the amount he sells at dates 2 and 3, as argues before.

Denote the money holding of the informed trader by $M$, where $M \geq 0$. Now the revenue maximization problem of (risk-neutral) informed trader can be stated as:

$$
\operatorname{Max}\left[\pi V_{H}+(1-\pi) V_{L}-P_{1}^{*}(B)\right] B
$$

subject to $\left(P_{1}^{*}(B)\right) B \leq M$

Although it is desirable to find exactly for what values of parameters $P_{1}^{*}(B)$ falls into the class of "regular supply functions" and thus increasing, this turns out to be a technically unmanageable problem, and so (by confining ourselves to appropriate parameter values) simply assume the following:

Assumption: Let $P_{1}^{*}(B)$ an increasing and continuous supply curve.

Some further assumptions about $P_{1}^{*}(B)$ and $M$ which will make the informed trader find it best to spend all his money $M$ to buy stocks at date 1 will considerably simplify the solution of this agent's maximization problem under the budget constraint. This can be achieved by assuming that $M$ is small enough, and $P_{1}^{*}(B)$ is sufficiently elastic around $B^{*}$, where $\left(P_{1}^{*}(B)\right) B=M$.

Since the main concern is the existence of stock markets where this new institutional design works the assumption is still valid. Now the problem becomes

$$
\operatorname{Max}\left(\pi V_{H}+(1-\pi) V_{L}\right) B-M
$$

subject to $B \geq 0$.

Actually the informed trader's optimization problem is a single point maximization problem due to the constraint. Hence, one should check whether $\left(P_{1}^{*}(B)\right) B=M$ admits a solution for $B$ or not.

$\left(P_{1}^{*}(B)\right) B=M \Leftrightarrow B=M /\left(P_{1}^{*}(B)\right)$ The left hand side of the equation namely $B$ is always an increasing function of $B$. In order for this equation to have a solution $M /\left(P_{1}^{*}(B)\right)$ should be a decreasing function of $\mathrm{B}$ in the same interval. If this is true then via Intermediate Value Theorem this equation admits a solution. If $P_{1}^{*}(B)$ is increasing $M /\left(P_{1}^{*}(B)\right)$ is obviously decreasing. As a conclusion $B=M /\left(P_{1}^{*}(B)\right)$ admits a solution via the Intermediate Value Theorem. Let us denote this solution by $B^{*}$.

If we substitute this obtained result $B^{*}$ into the prevailing market clearing price $P_{1}^{*}(B)$ we have $P_{1}^{*}\left(B^{*}\right)$. The informed trader should compare this value with $\pi V_{H}+(1-\pi) V_{L}$. If $P_{1}^{*}\left(B^{*}\right) \leq \pi V_{H}+(1-\pi) V_{L}$ then the informed trader will spend all of his money $M$ for buying the stock. He is indifferent between buying or not buying when there is equality. If $P_{1}^{*}\left(B^{*}\right)>\pi V_{H}+(1-\pi) V_{L}$ then the informed trader will buy nothing since he 
will incur a loss in this situation.

As a result we have observed that this kind of a stock market is close to trade- based manipulation. The local investors have complete information about the type of the entrant. The manipulator never enters the market since his expected profit is negative. The informed trader enters the market according to the prevailing market clearing price as discussed above. However he also has to respect his budget constraint.

Next step is to compare the investors' payoff in this version and in Allen and Gale (1992).

In Allen and Gale (1992) we have seen that the investor's payoff was defined as:

$$
U^{*}\left(B, P_{1}, Q_{1}\right)=Q_{1} \pi U\left(W_{H}\left(B, P_{1}, Q_{1}\right)\right)+Q_{1}(1-\pi) U\left(W_{L}\left(B, P_{1}, Q_{1}\right)\right)+\left(1-Q_{1}\right) U\left(W_{M}\left(B, P_{1}, Q_{1}\right)\right)
$$

In this new context the investor's payoff is:

$$
U^{* *}\left(B^{*}, P_{1}^{*}, Q_{1}\right)=Q_{1} \pi U\left(W_{H}\left(B^{*}, P_{1}^{*}, Q_{1}\right)\right)+Q_{1}(1-\pi) U\left(W_{L}\left(B^{*}, P_{1}^{*}, Q_{1}\right)\right)+\left(1-Q_{1}\right) U\left(W_{M}\left(B^{*}, P_{1}^{*}, Q_{1}\right)\right)
$$

If $U^{*}>U^{* *}$ is the case, the new model is not beneficial for the investors. Hence Allen and Gale's model with manipulation is desirable for the investors. If the inequality holds in the opposite direction it is beneficial for the investors to use this new model. If there is equality the investors are indifferent between Allen and Gale's model and the new one.

Actually, the investor's risk aversion is the critical assumption here. If the investors were also risk neutral as the large trader, the expected price for a stock is treated as the actual price from the agents in the stock market.

Under these circumstances the expected price of the stock in period 2 will be compared with the expected price of that stock in period 1 . There can be 3 cases:

i.If $\pi V_{H}+(1-\pi) V_{L}=P_{2}^{*}\left(B^{*}\right)>P_{1}^{*}\left(B^{*}\right)=Q_{1} \pi V_{H}+\left(1-Q_{1} \pi\right) V_{L}$ then the informed trader will spend his entire income on stock.

ii. If $\pi V_{H}+(1-\pi) V_{L}=P_{2}^{*}\left(B^{*}\right)=P_{1}^{*}\left(B^{*}\right)=Q_{1} \pi V_{H}+\left(1-Q_{1} \pi\right) V_{L}$ then the informed will be indifferent between buying and not buying.

iii. If $\pi V_{H}+(1-\pi) V_{L}=P_{2}^{*}\left(B^{*}\right)<P_{1}^{*}\left(B^{*}\right)=Q_{1} \pi V_{H}+\left(1-Q_{1} \pi\right) V_{L}$ then the informed trader will buy nothing.

\section{Numerical Example}

Let us try to give a numerical example that compares the two different versions of the stock market.

Set $V_{H}=12, V_{L}=10, \alpha=0.5, \pi=0.5, E=1, B=0.45, U=-\exp (-2 x)$. Now the posterior probability that the entrant is a manipulator becomes $Q_{1}=1-[\alpha /(\alpha+\beta)]=0.02$ and the posterior probability that the large trader is informed, given that no announcement is made at date 2 is:

$$
Q_{2}=Q_{1} \pi /\left(Q_{1} \pi+1-Q_{1}\right)=(0.98 * 0.5) /(0.98 * 0.5+0.02) \cong 0.96
$$

In Allen and Gale (1992) where selling only occurs at date 2, the market clearing price was

$$
P_{2}(B)=\frac{V_{H} Q_{2}(B) U^{\prime}\left(W_{H}(B)\right)+V_{L}\left(1-Q_{2}(B)\right) U^{\prime}\left(W_{L}(B)\right)}{Q_{2}(B) U^{\prime}\left(W_{H}(B)\right)+\left(1-Q_{2}(B)\right) U^{\prime}\left(W_{L}(B)\right)}=11.9
$$

However, in the new context where trading at date 3 is also permitted it becomes

$$
P_{2}^{*}\left(B^{*}\right)=\pi V_{H}+(1-\pi) V_{L}=0.5 * 12+0.5 * 10=11
$$

Let us similarly compute and compare the prevailing market clearing price (investor's supply) for both stock markets. In Allen and Gale (1992) where trading at date 3 is not allowed:

$$
P_{1}(B)=\frac{Q_{1}(B) \pi U^{\prime}\left(W_{H}(B)\right) V_{H}+Q_{1}(B)(1-\pi) U^{\prime}\left(W_{L}(B)\right) V_{L}+V_{L}\left(1-P_{1}(B)\right) U^{\prime}\left(W_{M}(B)\right) V_{L}}{Q_{1}(B) \pi U^{\prime}\left(W_{H}(B)\right)+Q_{1}(B)(1-\pi) U^{\prime}\left(W_{L}(B)\right)+V_{L}\left(1-Q_{1}(B)\right) U^{\prime}\left(W_{M}(B)\right)}=10.9
$$

In Allen and Gale (1992) the large trader buys stock at $P_{1}(B)=10.9$ and sells at $P_{2}(B)=11.9$, hence ending up with a revenue $B$. In this version the purchasing price $P_{2}^{*}\left(B^{*}\right)$ was 11 with the given parameters. If the buying price is $P_{1}^{*}\left(B^{*}\right)=10=V_{L}$ the revenue of the large trader is $B^{*}$. Every other price different from this yields a revenue less than $B^{*}$ for the local investors. However we know that $P_{1}^{*}\left(B^{*}\right)=10=V_{L}$ is impossible since $V_{H} \neq V_{L}$. Hence the expected revenue for the informed trader is less than $B^{*}$. In order to compare these two for this example $B^{*}$ should be computed. 
We know that $\left(P_{1}(B)\right) B=M$ is the situation in Allen and Gale (1992). Hence $M=10.9 * 0.45=4.905$. Now let us give the same income to the informed trader in our version and compute $B^{*}$.

$$
\begin{gathered}
\left(P_{1}^{*}\left(B^{*}\right)\right) B^{*}=M \\
\frac{V_{H} \pi U^{\prime}\left(W_{H}^{*}\left(B^{*}\right)\right)+V_{L}(1-\pi) U^{\prime}\left(W_{L}^{*}\left(B^{*}\right)\right)}{\pi U^{\prime}\left(W_{H}^{*}\left(B^{*}\right)\right)+(1-\pi) U^{\prime}\left(W_{L}^{*}\left(B^{*}\right)\right)}=\frac{4.905}{B^{*}} \\
W_{H}^{*}(B)=E V_{H}+\left(P_{1}^{*}\left(B^{*}\right)-V_{H}\right) B^{*}=12+\left[\left(4.905 / B^{*}\right)-12\right] B^{*} \\
W_{L}^{*}(B)=E V_{L}+\left(P_{1}^{*}\left(B^{*}\right)-V_{L}\right) B^{*}=10+\left[\left(4.905 / B^{*}\right)-10\right] B^{*}
\end{gathered}
$$

Hence

$$
\begin{gathered}
\frac{-12 * 0.5 * 24 * \exp \left(-33.81+24 B^{*}\right)-10 * 0.5 * 20 * \exp \left(-29.81+20 B^{*}\right)}{0.5 * 24 * \exp \left(-33.81+24 B^{*}\right)-0.5 * 20 * \exp \left(-29.81+20 B^{*}\right)}=\frac{4.905}{B^{*}} \\
B^{*} \cong 0.48
\end{gathered}
$$

We are not able compare the informed trader's expected revenue for both models. Although we know that his revenue is strictly less than 0.48 we do not know whether it is greater or less than 0.45 . However he may have still incentive to enter this version of the stock market if his expected profit is positive. For this, we have to compute $P_{1}^{*}\left(B^{*}\right)$ and compare it with $P_{2}^{*}\left(B^{*}\right)=\pi V_{H}+(1-\pi) V_{L}=0.5 * 12+0.5 * 10=11$.

$$
\begin{aligned}
P_{1}^{*}\left(B^{*}\right)= & {\left[0 . 5 * 1 2 * 2 * ( P _ { 1 } ^ { * } ( B ^ { * } ) - 1 2 ) ^ { * } ( P _ { 1 } ^ { * } ( B ^ { * } ) ) * \operatorname { e x p } \left(-2 *\left(12+\left(P_{1}^{*}\left(B^{*}\right)-12\right) * 0.48\right)+\right.\right.} \\
& \left.0.5 * 10 * 2 *\left(P_{1}^{*}\left(B^{*}\right)-10\right)^{*}\left(P_{1}^{*}\left(B^{*}\right)\right)\right)^{*} \exp \left(-2 *\left(10+\left(P_{1}^{*}\left(B^{*}\right)-10\right) * 0.48\right)\right] / \\
& {\left[0 . 5 * 2 * ( P _ { 1 } ^ { * } ( B ^ { * } ) - 1 2 ) * ( P _ { 1 } ^ { * } ( B ^ { * } ) ) ^ { \prime * } \operatorname { e x p } \left(-2 *\left(12+\left(P_{1}^{*}\left(B^{*}\right)-12\right) * 0.48\right)+\right.\right.} \\
& 0.5 * 2 *\left(P_{1}^{*}\left(B^{*}\right)-10\right) *\left(P_{1}^{*}\left(B^{*}\right)\right) * \exp \left(-2 *\left(10+\left(P_{1}^{*}\left(B^{*}\right)-10\right) * 0.48\right)\right]
\end{aligned}
$$

This equation admits no solution, hence an equilibrium price $P_{1}^{*}\left(B^{*}\right)$ due to a discontinuity problem. However we can make the following comparison:

If $P_{1}^{*}\left(B^{*}\right) \leq 11$ (assume without loss of generality the informed trader enters the market when he is indifferent) the informed trader has an incentive to enter the market since his expected revenue is non-negative.

Now consider the best possible scenario from the investors' side when the informed trader has an incentive to enter the market which is $P_{1}^{*}\left(B^{*}\right)=11$. For this situation let us compare $U^{*}$ and $U^{* *}$ namely the expected utilities of the investors for both models. For Allen and Gale (1992),

$$
\begin{aligned}
& U *\left(B, P_{1}, Q_{1}\right)=Q_{1} \pi U\left(W_{H}\left(B, P_{1}, Q_{1}\right)\right)+Q_{1}(1-\pi) U\left(W_{L}\left(B, P_{1}, Q_{1}\right)\right)+\left(1-Q_{1}\right) U\left(W_{M}\left(B, P_{1}, Q_{1}\right)\right) \\
= & -0.98 * 0.5 * \exp [-2 *(12+(10.9-11.9) * 0.45]-0.98 * 0.5 * \exp [-2 *(10+(10.9-11.0) * 0.45] \\
& -0.02 * \exp [-2 *(10+(10.9-11.9) * 0.45] \\
= & -0.49 * \exp (-23.1) *-0.49 * \exp (-20.81) *(-0.02) *(-19.1)
\end{aligned}
$$

For new version:

$$
\begin{aligned}
U * * & \left(B^{*}, P_{1}^{*}, Q_{1}\right)=Q_{1} \pi U\left(W_{H}\left(B^{*}, P_{1}^{*}, Q_{1}\right)\right)+Q_{1}(1-\pi) U\left(W_{L}\left(B^{*}, P_{1}^{*}, Q_{1}\right)\right)+\left(1-Q_{1}\right) U\left(W_{M}\left(B^{*}, P_{1}^{*}, Q_{1}\right)\right) \\
= & -0.98 * 0.5 * \exp [-2 *(12+(11-12) * 0.48]-0.98 * 0.5 * \exp [-2 *(10+(11-10) * 0.48] \\
& -0.02 * \exp [-2 *(10+(11-10) * 0.48] \\
= & -0.49 * \exp (-23.04) *-0.51 * \exp (-20.96)
\end{aligned}
$$

Let us multiply both equalities with $\exp (19.1)$ hence,

$$
\begin{aligned}
& \exp (19.1) * \mathrm{U} *\left(\mathrm{~B}, \mathrm{P}_{1}, Q_{1}\right)=-0.49 * \exp (-4)-0.49 * \exp (-1.71)-0.02 \cong-0.1318 \\
& \exp (19.1) * \mathrm{U} * *\left(\mathrm{~B} *, \mathrm{P}_{1}^{*}, Q_{1}\right)=-0.49 * \exp (-3.94)-0.51 * \exp (-0.96) \cong-0.2138
\end{aligned}
$$

Notice that $U^{*}>U^{* *}$, thus we can say that if entry occurs the utility loss in our version is more than the utility loss in Allen and Gale's model (even in the best possible case!).

If $P_{1}^{*}\left(B^{*}\right)>11$, the informed trader prefers to stay out since his expected revenue is negative. However, this is the best possible situation for the local investors since their utility will be $U^{* *}=0$, which is greater than any negative number, hence any possible utility. Thus, we can say preventing entrance is the best thing for the investors in such a stock market. 


\section{Conclusion}

As a conclusion, the new model is desirable for the local investors in this example when entry is entirely prevented. If there is entry, the local investors would prefer Allen and Gale's construction. Thus, they will allow manipulation.

Instead of introducing a high discount factor between date 2 and date 3 or making auxiliary ad-hoc assumptions as done in Allen and Gale (1992), we can let the local investors to consider allowing trade also at date 3 as done here. If the basic parameters are set like in this example, the local investors will tend to preclude trade at date 3 hence automatically prefer Allen and Gale's model to our model. In addition the large traders will not object to that preclusion and manipulation will be allowed.

Furthermore, one can arrange the basic data in such a way that this new model is desirable. By increasing the possibility of manipulation we can reduce the prevailing market clearing prices for both periods and make comparisons after that.

Here it is have shown that a modification in the institutional design rules out entry of manipulators. In the particular context of Allen and Gale (1992), if the design turns out to also deter entry of "informed" traders, then the investors clearly prefer the new design to Allen and Gale's design under which they incur an expected positive loss. A more thorough comparison between the outcomes these two designs yield is yet to be done when "informed" traders still have incentives to enter the market under the new design.

Throughout this paper there was no discount factor. If this is taken into account, we are not able to combine the prevailing prices on date 2 and date 3 so easily. If we introduce a high discount factor only between date 2 and date 3 this thesis will look like Allen and Gale (1992) model. However the magnitude of this discount factor plays an important role. Also situations change when the discount factor is placed not only between date 2 and date 3 but also between date 1 and date 2 . In any case it must be extensively analyzed and new market clearing prices must be computed under these circumstances.

\section{References}

Allen, F., \& Gale, D. (1992). Stock Price Manipulation. Review of Financial Studies, 5(3), 503-529. http://dx.doi.org/10.1093/rfs/5.3.503

Benabou, R., \& Laroque, G. G. (1992). Using Privileged Information to Manipulate Markets: Insiders, Gurus, and Credibility. The Quarterly Journal of Economics, 107(3), 921-958. http://dx.doi.org/10.2307/2118369

Cho, I. K., \& Kreps, D. M. (1987). Signaling Games and Stable Equilibria. The Quarterly Journal of Economics, 102(2), 179-221. http://dx.doi.org/10.2307/1885060

Hart, O. D. (1977). On The Profitability of Speculation. The Quarterly Journal of Economics, 91(4), 579-597. http://dx.doi.org/10.2307/1885883

Ilalan, D. (2001) How to Prevent Trade Based Stock Price Manipulation. Bilkent University, Department of Economics, M. A. Retrieved from http://www.thesis.bilkent.edu.tr/0001822.pdf

Veysoglu, A. N. (1996). Game Theoretic Modeling of Stock Exchanges. METU M.S. Thesis.

\section{Copyrights}

Copyright for this article is retained by the author(s), with first publication rights granted to the journal.

This is an open-access article distributed under the terms and conditions of the Creative Commons Attribution license (http://creativecommons.org/licenses/by/3.0/). 